\title{
Effect of cupping therapy on the level of pain and neuromuscular variables in women with low back pain
}

\author{
Letícia Carvalho Pereira, Deborah Hebling Spinoso
}

Universidade Estadual Paulista, UNESP, Marília (SP), Brazil.

\begin{abstract}
Background: Cupping therapy is a common technique in the field of traditional Chinese medicine, which through sucking on the skin mainly results in pain relief. Objectives: To analyze the effect of cupping therapy on pain intensity, muscle co-contraction and trunk extensor muscle strength in women with low back pain. Methods: 26 women participated, divided into: LBPgroup $(n=13)$, and control group $(n=13)$. The level of pain, isometric strength of trunk extensor muscles and co-contraction of superficial and deep trunk muscles were evaluated. The cupping therapy treatment consisted of 10 sessions, and after the volunteers were reevaluated. Anova Repeated Measures were used. Results: There was a $40.1 \%$ reduction in pain level, a $13.6 \%$ increase in trunk extensor strength, and a decrease in contraction between rectus abdominis and iliocostalis for GDL after treatment. Conclusion: 10 sessions of cupping therapy assist in reducing pain and improving trunk strength in young people with lower back pain.

Keywords: Electromyography; Traditional Chinese Medicine; Physical Therapy.
\end{abstract}

\section{BACKGROUND}

Low back pain (LBP) is usually defined as pain located below the margin of the last ribs and above the lower gluteal lines with or without pain in the lower limbs. It is a problem that affects $80 \%$ of adults at some point in life, and is among the top 10 causes of medical appointments and, every year, 5 to $10 \%$ of workers lose more than seven days of work due to pain, with great impact on productivity and reduction of the economy ${ }^{(1)}$.

LBP affects mainly individuals between 20 and 55 years old, with a higher prevalence in females ${ }^{(2)}$. Some authors believe that women are at greater risk than men because of anatomo-functional peculiarities that, when combined, can facilitate the appearance of low back pain.

They have smaller stature, muscle mass and bone density, greater joint fragility and less adaptation to physical effort. In addition, the sum of the burden imposed by the performance of domestic tasks increases this risk ${ }^{(3)}$.

Among the possible causes of low back pain, common mechanical LBP or nonspecific LBP represents a large part of the pain reported by the population. This type of LBP is characterized by the absence of structural alteration, that is, there is no reduction in the space of the intervertebral disc, compression of nerve roots, bone or joint injury, scoliosis or severe lordosis that can lead to pain in the spine ${ }^{(3)}$. Nonspecific LBP is multifactorial.
Among the causes, lower back pain can be associated with neuromuscular imbalances, which result in less trunk stabilization and, consequently, greater overload on joint structures during daily activities $^{(4)}$. This difficulty in stabilizing the spine is related to the inefficiency of recruiting the deep stabilizing muscles, increasing the contraction of the superficial trunk muscles and reducing the fatigue resistance capacity of the trunk extensors ${ }^{(5)}$.

In addition, Hodges and Richardson demonstrated that the delay in anticipatory activation of the deep abdominal muscles before performing the functional movements can also be one of the causes of the development and recurrence of LBP. The delay in recruiting this musculature indicates a deficit in motor control and may not provide efficient segmental rigidity during daily tasks and result in inadequate protection of the structural elements of the spine ${ }^{(6,7)}$.

Other characteristics related to the individual's lifestyle, such as excess body mass, physical inactivity and prolonged stay in certain positions, can contribute to worsening the pain ${ }^{(8)}$.

In view of the high prevalence of LBP and the high public spending on drugs and absence from work related to this population, more and more treatments are being sought that can act on the neuromuscular causes of nonspecific low back pain, thus reducing its intensity and recurrence ${ }^{(1)}$. 
Among the various physiotherapy procedures, one of the most used is manual therapy, which aims to promote pain relief through vertebral manipulations and muscle relaxation and, consequently, improve the biomechanical function of tissues ${ }^{(9)}$. In addition to manual therapy, physiotherapy relies on other techniques and resources for the purpose of analgesia, such as electrotherapy and kinesiotherapy, the Pilates method being the most commonly performed for individuals with LBP. ${ }^{(5)}$.

In addition to all the aforementioned resources and techniques for the treatment and / or symptomatic control of LBP, the cupping therapy is currently being used as a complementary therapy in order to reduce the symptoms of chronic non-specific low back pain. Cupping therapy is a common therapy in the field of Traditional Chinese Medicine with a long history, in which it is used to decrease local symptoms of chronic pain. Currently, more and more patients are showing interest in using cupping therapy for the treatment of low back pain, as they believe that it is more effective and safer ${ }^{(9)}$.

There are many types of techniques using the cupping therapy, including dry suction cup, wet suction cup, holding cup, setting in motion, stirring, fast cup and balancing cup. The dry suction cup is most commonly used in clinical practice as it is the safest form of application. In this technique, the skin is sucked into the suction cup without drawing blood. This suction generates a negative pressure responsible for stimulating the elimination of toxins at the application site and activating anti-inflammatory enzymes, which results in pain relief and muscle relaxation ${ }^{(9)}$.

Authors like Wang et al. ${ }^{(9)}$ (2017), Teut et al. ${ }^{(10)}$ (2018), Kim et al. ${ }^{(11)}$ (2011), among others, analyzed the efficacy and safety of cupping therapy on the level of pain in a patient with LBP and obtained significant results, revealing that they are potentially safe and cost-effective and with an average pain reduction of $50 \%$ to $75 \% \%$. In addition, they compared the effectiveness of the types of cupping therapy in decreasing the symptoms of LBP and found that there is no significant difference between the types of suction cup.

Although some studies have shown that cupping therapy can reduce pain in patients with nonspecific low back pain, its effect on the neuromuscular variables involved in the cause of LBP is not yet known. In other words, if the decrease in pain provided by treatment with cupping therapy can influence the activation pattern of the stabilizing muscles of the trunk and their strength.

In this sense, the objective of this study is to analyze the effect of treatment with cupping therapy on the intensity of low back pain, muscle co-contraction and strength of the trunk extensor muscles in young people with nonspecific low back pain. It is expected that after the treatment, there will be a decrease in the level of pain and co-contraction of the superficial muscles of the trunk, as well as an increase in the strength of the posterior muscles of the trunk.

\section{METHODS \\ Participants}

26 women were selected, aged between 18 and 25 years, female, sedentary, divided into two groups: LBP group (LBPG), and control group (CG). For LBPG, young people were recruited who had a report of recurrent LBP (lasting more than 12 weeks), with no specific etiology, located below the margin of the last ribs (costal margin) and above the lower gluteal lines. For CG, young people were recruited who did not complain of low back pain.

We did not include individuals who were being treated with anti-inflammatory or analgesic 72 hours before the evaluation and who showed signs of nervous compression or other rheumatic diseases.

All volunteers signed the Free and Informed Consent Form and the present study was submitted and approved by the Local Ethics Committee.

The characteristics of the sample are shown in table 1.

Table 1: Characteristics of participantes

\begin{tabular}{|c|c|c|}
\hline & LBP Group & Control Group \\
\hline Age (years) & $22,53 \pm 1,85$ & $21,84 \pm 1,57$ \\
\hline Body Mass (kg) & $61,54 \pm 13,54$ & $55,19 \pm 6,64$ \\
\hline Height (cm) & $163,84 \pm 5,59$ & $161,30 \pm 5,00$ \\
\hline $\mathrm{BMI}\left(\mathrm{Kg} \cdot \mathrm{m}^{-2}\right)$ & $23,02 \pm 5,57$ & $21,20 \pm 2,38$ \\
\hline $\begin{array}{l}\text { Roland Morris } \\
\text { Questionnaire } \\
\text { (points) }\end{array}$ & $5,15 \pm 3,86$ & $0,61 \pm 1,04$ \\
\hline
\end{tabular}

"Note: LBP: Low back pain; BMl: Body mass index. Values of mean and standard deviation.

\section{Evaluation Procedure}

The evaluation procedures were performed in a single day. First, anamnesis, anthropometric data collection, application of the Rolland Morris questionnaire and quantification of pain level using the visual analog scale (VAS) were performed. 
Then, the tensile strength test with dynamometer, Biering Sorensen test and postural disturbance test were performed. The test sequence was determined by directed randomization.

After the evaluation, treatment with cupping therapy was started. At the end of 10 sessions, the volunteers were reassessed.

\section{Analogic Visual Scale}

The visual analog scale (VAS) is a semiobjective scoring system used to quantify the intensity of pain ${ }^{(12)}$. The VAS is typically a $100 \mathrm{~mm}$ long horizontal straight line, which describes the painful intensity (no pain; worst possible pain, for example) at each end of the line. This scale has been used extensively in medicine, and is usually filled out by the patient himself ${ }^{(13)}$.

\section{Biering Sorensen Test}

The Biering-Sorensen test aims to assess the muscle fatigue of spine erectors, in which resistance is generated by the individual's body mass, subjecting all those evaluated to a similar load and proportional to their strength ${ }^{(14)}$. For its execution, the volunteer is placed in the prone position, with the pelvis and lower limbs fixed to the evaluation table with velcro. In addition, the evaluator advises the volunteer to keep the upper limbs crossed in front of the chest and the trunk (Figure 1) ${ }^{(15-17)}$.

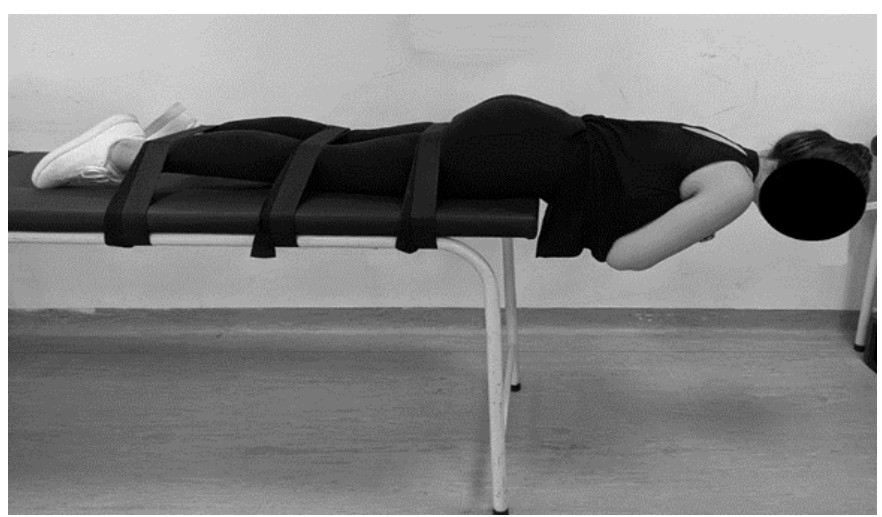

Figure 1. Position of the Biering-Sorensen test.

\section{Isometric Strength of Trunk Extenders}

The test of static strength of the lumbar muscles was performed with the volunteer in an orthostatic position, with a semi-flexed trunk, legs and arms extended, as shown in figure 2 . The subject held the instrument bar and, at the evaluator's command,

performed a trunk extension movement, seeking to exert maximum strength from the lumbar musculature ${ }^{(18)}$. The dorsal dynamometer (Oswaldo Filizola Ltda®, São Paulo, Brazil) was used for data collection. The volunteers performed the test three times, with an interval of 5 minutes between attempts, with the average of the values of the three attempts being calculated.

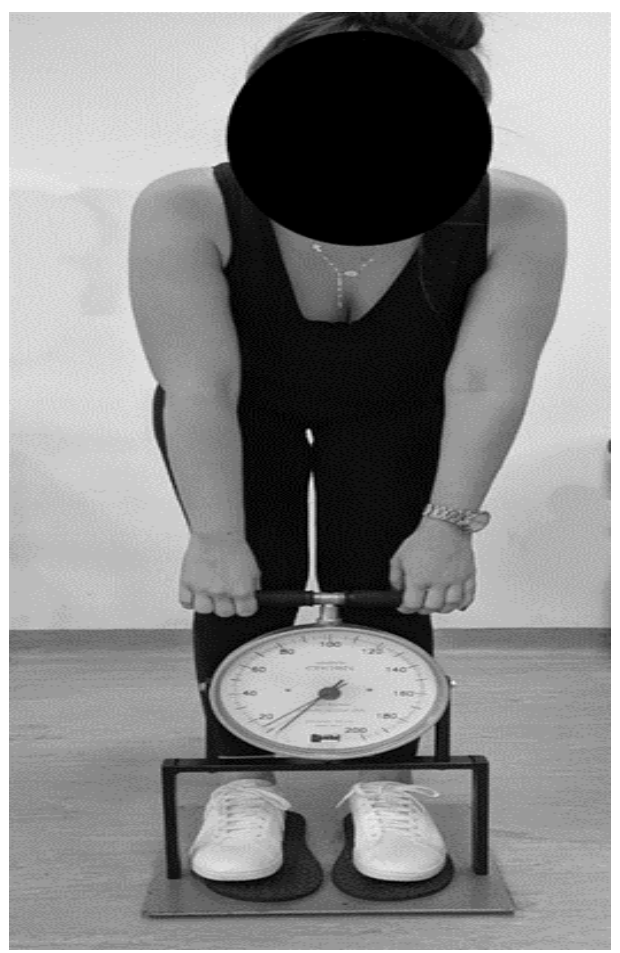

Figure 2. Assessment of the isometric strength of the trunk extensors.

\section{Postural Disturbance Test}

The volunteer was positioned in an orthostatic position and performed the elevation of her right arm, performing shoulder flexion with an extended elbow. Five movements were performed, from the relaxed vertical position, with the upper limbs at the side of the body. After the verbal command of the evaluator, the volunteer performed the movement as quickly as possible until reaching the shoulder flexion $180^{\circ(19)}$. The volunteers were instructed to prioritize movement speed over precision. The test was performed unilaterally, being performed on the patient's side of greatest pain, or the dominance side, if she did not have the side of greatest pain.

Prior to the test, the volunteers were familiarized with three repetitions of the movement. During this test, the electromyographic data of the trunk muscles were collected.

\section{Electromyography}

The electromyographic evaluation was performed during the postural disturbance test and Biering Sorensen test. To capture the electromyographic signals, an 8-channel biological signal acquisition module (Myosystem-BR1) was used, Myosystem-BR1 software, calibrated with a 
sampling frequency of $2000 \mathrm{~Hz}$, a total gain of 2000 times (20 times in the sensor and 100 times in the equipment), $20 \mathrm{~Hz}$ high-pass filter, $500 \mathrm{~Hz}$ low-pass filter. Active electrodes were used, in bipolar configuration, with a capture area of $1 \mathrm{~cm}$ in diameter and inter-electrode distance of $2 \mathrm{~cm}$. Prior to placing the electrodes, trichotomy and skin cleaning with alcohol was performed ${ }^{(20)}$. The electrodes were fixed on the trunk, unilaterally, being placed on the patient's side of greatest pain, or the dominance side, if she did not have the most pain side, on the muscles: transverse abdomen (TA), multifidus (MU), rectus abdominis (RA) and lumbar iliocostal (LI).

\section{Data Analysis}

\section{Muscle Co-Contraction}

Muscle co-contraction data were collected during the Biering Sorensen test and Postural Disturbance Test. The electromyographic signal was processed using routines developed in a Matlab environment (Mathworks ${ }^{\circledR}$ ), using a $20-500 \mathrm{~Hz}$ bandpass filter. Subsequently, the signals were rectified and smoothed, using a 4th order butterworth filter with a $6 \mathrm{~Hz}$ cutoff frequency.

The calculation of the percentage of co-contraction between the TA and MU and RA and LI muscles will be performed from the linear envelope values, according to the equation below ${ }^{(21,22)}$.

\section{$\% \mathrm{COCON}=2 \mathrm{X}$ common area of $\mathrm{A} \& \mathrm{~B} \times 100$ Area of $A+$ area of $B$}

$\%$ COCON is the percentage of co-contraction between two antagonistic muscles $A$ and $B$, such as $\mathrm{MU}$ and TA. Area $A$ is the smoothed curve of EMG activity of muscle $A$ and area $B$ is the smoothed curve of EMG activity of muscle $B$; The common area $A \& B$ is the common curve of EMG activity of muscle $A$ and muscle $B^{(22)}$.

\section{Muscle Strength}

For the analysis of the muscular strength data, the average of the three attempts of the isometric strength test of the trunk extensors, carried out by the volunteers, was performed and the value was normalized by the body mass.

\section{Treatment with Cupping Therapy}

The treatment with cupping therapy consisted of 10 sessions, performed twice a week, on nonconsecutive days, lasting 10 minutes each session. Six size 1 suction cups (Dong Yang ${ }^{\circledR}$ ) were used in the lower back. The volunteers were placed in prone position and three suction cups were placed on the right side and three on the left side, as shown in figure 3 .

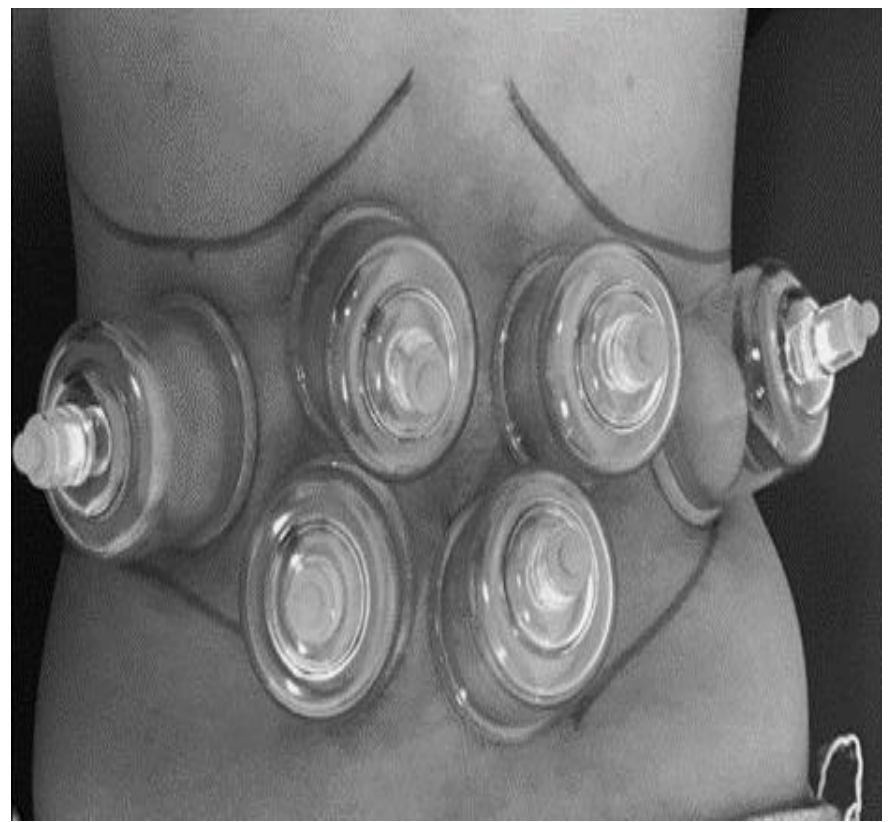

Figure 3. Positioning of suction cups during treatment.

The suction cups were fixed to the volunteers' skin using a manual suction pump. The therapist performed four suctions on each suction cup. Before placing the suction cups, the region to be treated was cleaned with alcohol to remove impurities and possible chemical substances present in the region due to the use of body moisturizers ${ }^{(23)}$. The treatment protocol was created by the authors of the study.

\section{Statistical Analysis}

Statistical analysis was performed using the PASW statistics 18.0® (SPSS) software. After checking the normality and homogeneity of the data, the Anova Repeated Measurements test was applied to compare the variables before and after treatment as well as to compare the groups. In all statistical tests, a significance level of $p<0.05$ was adopted

\section{RESULTS}

The Anova Repeated Measures test showed that there was a group effect $(p=0.001 ; F=$ 16.712) and condition effect ( $p=0.027$; $F=$ 5.106). There was no interaction between the groups evaluated and the conditions analyzed ( $p$ $=0.680, \mathrm{~F}=0.400$ ), as shown in Table 2 . 
Table 2. Anova Repeated Measures for the treatment with wind therapy in young women with low back pain.

\section{P Values}

Group Effect Condition Effect

Group Interaction X Condition

\begin{tabular}{llll} 
VAS $(\mathrm{cm})$ & $0,001^{*}$ & $0,048^{\star}$ & 0,392 \\
Strength of trunk extensors $\left(\mathrm{Nm}^{*} \mathrm{~kg}^{-1}\right)$ & $0,047^{*}$ & $0,011^{*}$ & 0,654 \\
& & & \\
Co-contraction (MU/TA)- BS & 0,332 & 0,940 & 0,672 \\
Co-contraction (RA/LI) - BS & 0,992 & 0,850 & 0,069 \\
Co-contraction (MU/TA) - PD & 0,241 & 0,065 & 0,895 \\
Co-contraction (RA/LI) -PD & 0,051 & $0,002^{\star}$ & 0,534 \\
\hline
\end{tabular}

"Note: VAS: Visual Analog Scale. MU: Multifid muscle. TA: Transverse abdomen mucle. RA: rectus abdominis mucle. LI: Lumbar lliocostal muscle. BS: Biering Sorensen. PD: Postural disturbance.

Regarding the comparison between groups, there was a significant difference for the pain variable assessed using the Visual Analogue Scale, with $92.1 \%$ greater in the LBP group compared to the control group before treatment and $100 \%$ after treatment. For the trunk extensor strength variable, there was a difference of $17.8 \%$ in the initial assessment and $12 \%$ in the final assessment, as shown in Table 3.

Table 3. Effect of cupping therapy on pain and strength of trunk extensors in women with and without low back pain.

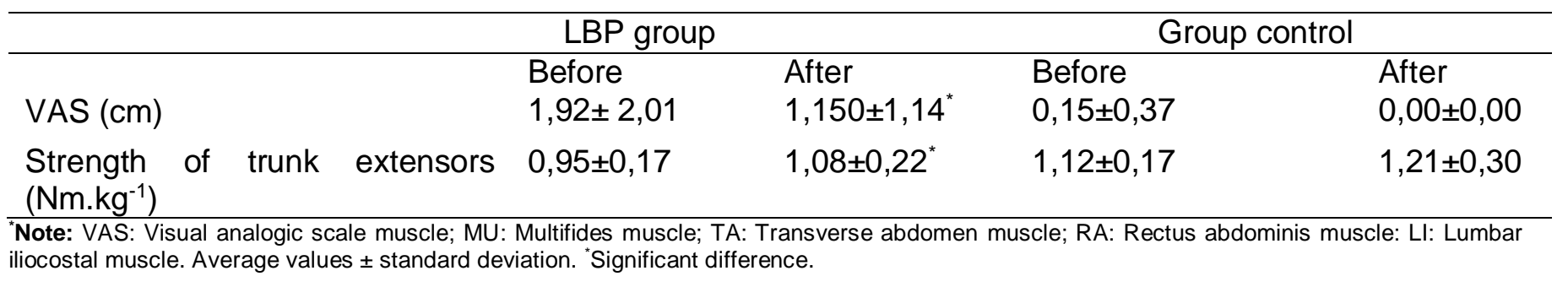

Regarding the comparison between conditions, there was a significant difference for pain, with a reduction of $40.1 \%$, an increase of $13.6 \%$ in the strength of the trunk extensors and less co- contraction between RA and $\mathrm{LI}$ during the postural disturbance test, for LBPG, as shown in tables 3 and 4.

Table 4. Effects of cupping therapy on co-contraction during the Sorensen test and postural disturbance test.

\begin{tabular}{llllc}
\hline & \multicolumn{2}{c}{ Low back pain group } & \multicolumn{2}{c}{ Group control } \\
\hline & \multicolumn{1}{c}{ Before } & After & Before & After \\
Co-contraction (MU/TA) & $60,26 \pm 20,51$ & $58,34 \pm 21,72$ & $49,38 \pm 23,82$ & $53,41 \pm 27,68$ \\
Co-contraction (RA/LI) & $37,70 \pm 28,42$ & $52,24 \pm 31,05$ & $51,93 \pm 23,00$ & $36,33 \pm 20,09$ \\
Co-contraction (MU/TA) & $73,11 \pm 23,41$ & $63,43 \pm 21,59$ & $64,03 \pm 22,67$ & $52,23 \pm 28,82$ \\
Co-contraction (RA/LI) & $60,09 \pm 24,25$ & $47,93 \pm 21,26^{*}$ & $70,67 \pm 21,38$ & $67,72 \pm 26,32$
\end{tabular}




\section{DISCUSSION}

The present study supports the initial hypothesis that after the treatment with cupping therapy, there would be a decrease in the level of pain and co-contraction of the superficial muscles of the trunk, as well as an increase in the strength of the posterior muscles of the trunk. However, the authors did not observe a significant change in the co-contraction of the deep trunk muscles, as expected.

Regarding the level of pain, considered one of the most disabling symptoms of individuals, this study showed that cupping therapy is a physiotherapeutic resource that can reduce the Visual Analogue Scale (VAS) score in young individuals with low back pain. The result found in the study corroborates the findings of $\mathrm{Al}$ Bedah et al (2015) and Wang et al (2017), which also showed a significant reduction in the level of pain after suction cup therapy in individuals with low back pain.

This decrease in pain in patients with LBP after cupping therapy treatment can be explained by energetic and physiological bases. Until the end of the century. XVIII the explanation given by western doctors was through the redistribution and balance of the four cardinal "moods", in which diseases and pain were explained by the imbalance between the moods (heart, respiratory system, liver and spleen), giving rise to Humoral Theory. In this sense, cupping therapy would have as main benefit the balance between the humors, reducing mainly the symptoms of pain ${ }^{(23)}$. Subsequently, the explanations given about the action of cupping therapy revolved around human physiology, mainly in the formation of antitoxins within the tissues stimulated by the suction cup.

According to the author Lowe (2017), one of the main explanations about the suction cup effect in reducing pain is through the negative pressure generated by suction of the cup on the patient's skin. This suction generated by the suction cup, makes a pressure difference between the patient's skin and the blood vessels, causing an almost immediate vasodilation in the supercapillary capillaries and then produces a localized hyperemia and a bruise, in which it attracts macrophages that phagocytize erythrocytes and stimulate them to produce an enzyme (heme oxygenase-1). Heme oxygenase is an essential enzyme for heme catabolism, which in turn is divided into biliverdin (BV), bilirubin (BR), carbon monocyte (CO) and iron, which have antioxidant, anti-inflammatory, antiproliferative and neuromodulatory effects, thus reducing the symptoms of local and systemic pain ${ }^{(23)}$.

Regarding the level of muscle contraction, which according to Candotti et al (2009) can be interpreted as a neuromuscular pattern in which two or more antagonistic muscles stabilize or adjust to each other so that a harmonic movement or postural adjustment can be produced, is altered in individuals with low back pain. According to the literature, the maintenance of trunk stability occurs through the cocontraction of the deep trunk muscles (multifidus and transverse abdomen) during movements. However, in the population with nonspecific low back pain, the weakness of the stabilizing musculature can result in increased contraction of the superficial muscles (iliocostal and rectus abdominis) as a compensatory strategy for pain, which can contribute to segmental instability ${ }^{(24)}$.

Our study showed that after 10 sessions of cupping therapy there was decreased activation of the superficial muscles (LI / RA). This alteration may have a beneficial clinical implication for these individuals, given that the increase in joint stiffness provided by greater contraction of the superficial muscles can be harmful to the spine, since it reduces the ability of the musculoskeletal system to adapt to overload ${ }^{(5)}$.

Regarding the change in the muscular strength of the trunk extensors of individuals who have reported low back pain, it can be related to changes in neural adaptation and the consequent modification in motor control due to chronic pain ${ }^{(25)}$, which can generate functional limitations, and consequent limitation in activities of daily living ${ }^{(26)}$.

The women with LBPin this research had an average strength of the trunk extensors in the traction test before the treatment with a suction cup of $0.95 \mathrm{Nm} . \mathrm{Kg}$, while after the treatment with the suction cups the touch of the trunk extensors resulted in $1,08 \mathrm{Nm} . \mathrm{Kg}$, thus increasing by $13.6 \%$. It is believed that this difference observed in the study can be explained mainly by the reduction in the level of pain of the volunteers, which can facilitate muscle recruitment and consequent better performance in the traction test.

The use of suction cups in physiotherapy sessions is becoming an increasingly common tool to be used by professionals, especially when their purpose is analgesia. However, the authors point out that despite the positive changes in neuromuscular variables and in the level of pain in individuals with low back pain, this tool should be used as part of the treatment and fits in one of the several analgesic procedures available today in physical therapy, such as for example the use of manual therapy, electrothermal phototherapy, kinesiotherapy, among others and that it does not 
replace the conventional treatment of physiotherapy.

\section{Study limitations}

The present study was carried out with a small sample size, which limits the extrapolation of these results to other populations. It is suggested that further studies be carried out in order to investigate the benefits of cupping therapy in patients with LBPand its influence on the activities of daily living in this population.

\section{CONCLUSION}

After 10 sessions of cupping therapy, there was a decrease in the level of pain, an increase in the isometric strength of the trunk and less cocontraction between RA and $L I$ in young women with low back pain.

\begin{abstract}
Authors' contributions: LCP defined the concept of the study, created the hypothesis and wrote the original proposal. LCP, DHS were involved in the critical review of the study proposal and the manuscript and Wrote this study protocol. All authors read and approved the manuscript.
\end{abstract}

Financial support: Not declared.

Conflict of interest: The authors declare that there was no conflict of interests.

\section{REFERENCES}

1. Almeida DC, Kraychete DC. Dor lombar - uma abordagem diagnóstica. Rev Dor. 2017;18(2):173-7.

2. Junior MH, Goldenfum MA, Siena C. Lombalgia Ocupacional. Rev Assoc Med Bras. 2010;56(5):583-9.

3. Lizier DT, Perez MV, Sakata RK. Exercícios para Tratamento de Lombalgia Inespecífica. Editora Elsevier. 2012;62(6):838-846.

4. Pereira NT, Ferreira LAB, Pereira WM. Efetividade de exercícios de estabilização segmentar sobre a dor lombar crônica mecânico-postural. Fisioter Mov. 2010;23(4):605-14.

5. Silveira APB, Nagel LZ, Pereira DD, Morita AZ, Spinoso DH, Navega MT, et al. Efeito imediato de uma sessão de treinamento do método Pilates sobre o padrão de co-contração dos músculos estabilizadores do tronco em indivíduos com e sem dor lombar crônica inespecífica. Fisioter Pesqui. 2018;25(2):173181.

6. Hodges PW, Richardson CA. Inefficient muscular stabilization of the lumbar spine associated with low back pain. Spine. 1996;21(22):2640-50.

7. Hodges PW, Richardson CA. Altered trunk muscle recruitment in people with LBPwith upper limb movement at different speeds. Arch Phys Med Rehabil. 1999;80(9):1005-12.

8. Graup S, Bergmann M, Bergmann GG. Prevalência de dor lombar inespecífica e fatores associados em adolescentes de Uruguaiana/RS. Revista Brasileira de Ortopedia. 2014;49(6):661-667.

9. Wang Y, Qi Y, Tang F, Li FM, Li QH, Xu CP, et al. The effect of cupping therapy for low back pain: A meta-analysis based on existing randomized controlled trials. Journal of Back and Músculos keletal Rehabilitation. 2017;30(6): 1187-1195.

10. Teut M, Ullmann A, Ortiz M, Rotter G, Binting S, Cree $M$, et al. Pulsatile dry cupping in chronic LBP- a randomized three-armed controlled clinical trial. BMC Complementary and Alternative Medicine. 2018;18:115.

11. Kim JI, Kim TH, Lee MS, Kang JW, Kim KH, Choi $\mathrm{JY}$, et al. Evaluation of wet-cupping therapy for persistent non-specific low back pain: a randomized, waiting-list controlled, open-label, parallel-group pilot trial. Trials. 2011 Jun 10;12:146.

12. Gaynor JS, Muir WW. Manual de controle da dor em Medicina Veterinária. 2.ed. São Paulo: MedVet, 2009. 643p

13. Holton LL, Scott EM, Nolan AM, Reid J, Welsh E, Flaherty D. Comparison of three methods used for assesment of pain in dogs. Journal of the American Veterinary Medical Association, v.212, p.61-66, 1998.

14. $\mathrm{Ng} J K$, Richardson CA, Jull GA. Electromyographic amplitude and frequency changes in the iliocostalis lumborum and multifidus muscles during a trunk holding test. Phys Ther. 1997;77(9):954-61.

15. Crossman K, Mahon M, Watson PJ, Oldham JA, Cooper RG. Chronic low back pain- associated paraspinal muscle dysfunction is not the result of a constitutionally determined "adverse" fibertype composition. Spine. 2004;29(6):628-34.

16. Demoulin C, Vanderthommen M, Duysens C, Crielaard JM. Spinal muscle evaluation using the Sorensen test: a critical appraisal of the literature. Joint Bone Spine. 2006;73(1):43-50.

17. Candotti CT, Loss JF, Pressi AMS, Castro FAS, Torre ML, Melo MO, et al. Electromyography for assessment of pain in low back muscles. Phys Ther. 2008;88(9):1061-7.

18. Cavazzoto TM, Tratis L, Ferreira SA, Fernandes 
SA, Queiroga MR. Desempenho em testes de força estática: comparação entre trabalhadores hipertensos e normotensos. Rev Assoc Med Bras. 2012;58(5):574-579.

19. Massé-Alarie $H$, Flamand $V H$, Moffet $H$, Schneider C. Corticomotor control of deep abdominal muscles in chronic LBPand anticipatory postural adjustments. Exp Brain Res. 2012; 218(1):99-109.

20. Gonçalves M, Barbosa F. Análise de parâmetros de força e resistência dos músculos eretores da espinha lombar durante a realização de exercício isométrico em diferentes níveis de esforço. Revista Brasileira de Medicina do Esporte. 2005;11(2):1-6

21. Winter DA. Biomechanics and motor control of human movement. Wiley-Interscience Plubication, 2ed., 1990.

22. Candotti CT, Loss JF, Begatini D, Soares DP, Rocha EK, Oliveira AR, Guimarães ACS. Cocontraction and economy of triathetes and cyclists at different cadences during cycling motion. Journal of Electromiography and Kinesiology. 2009;19(5):915-21.

23. Lowe DT. Cupping therapy: An analysis of the effects of suction on skin and the possible influence on human health. Complementary Therapies in Clinical Practice. 2017;29:162-168.

24. Hall L, Tsao H, MacDonald D, Coppieters M, Hodges PW. Immediate effects of cocontraction training on motor control of the trunk muscles in people with recurrent low back pain. Journal of Electromyography and Kinesiology. 2009;19(5):763-73

25. Nava GTA, Tozim BM, Morcelli MH, Navega MT. Influence of pain in strength, resistance and recruitment of trunk muscles. $\mathrm{Br} J$ Pain. 2018;1(4):310- 5.

26. Moura CC, Chaves ÉCL, Cardoso ACLR, Nogueira DA, Corrêa HP, Chianca TCM. Cupping therapy and chronic back pain: systematic review and meta-analysis. Rev Lat Am Enfermagem. 2018 Nov 14;26:e3094. 